\title{
Arterial spin labeling in patients with schizophrenia: a systematic review
}

\author{
Tiago M. Guimarães1, João Paulo Machado-de-Sousa1,2, José A. S. Crippa1,2, Mara R. C. Guimarães ${ }^{1}$, \\ JaIME E. C. HALlaK 1,2
}

- Department of Neuroscience and Behavior, Faculdade de Medicina de Ribeirão Preto, Universidade de São Paulo (FMRP-USP), Ribeirão Preto, SP, Brazil.

${ }_{2}^{2}$ National Institute for Science and Technology - Translational Medicine (INCT-TM), National Counsel of Technological and Scientific Development (CNPq), Brazil.

Received: 8/22/16 - Accepted: 10/29/16

DOl: 10.1590/0101-60830000000103

\begin{abstract}
Background: Neuroimaging studies are an invaluable source of information about the physiopathology of schizophrenia. Arterial spin labeling (ASL) is a new magnetic resonance technique (MRI) that is able to effectively evaluate brain function without the use of radiation. Objective: To make a systematic review of studies using ASL to compare resting-state regional cerebral blood flow ( $\mathrm{rCBF}$ ) patterns in patients with schizophrenia and healthy controls. Methods: Original articles were searched for on PubMed, Scopus, Web of Science and PsycINFO electronic databases. The search terms used were 'arterial', 'spin', 'labeling', and 'schizophrenia'. Only studies comparing resting-state rCBF were included, a qualitative synthesis was then performed. Results: Ten articles were included in the review among a total of 22. Decreased rCBF in schizophrenia patients was described in the anterior cingulate, cuneus, fusiform gyrus, frontal lobe, left middle frontal gyrus, inferior frontal gyrus, lingual gyrus, middle occipital gyrus, and parietal lobe. The putamen was the only region with increased rCBF in schizophrenia. Discussion: The evidence of the studies reviewed lends support to the concept of hipofrontality in schizophrenia. rCBF alterations were found in regions classically associated with schizophrenia. ASL seems to be valid, and reliable tool to assess schizophrenia.
\end{abstract}

Guimarães TM et al. / Arch Clin Psychiatry. 2016;43(6):151-6

Keywords: Arterial spin labeling, schizophrenia, functional neuroimaging.

\section{Introduction}

Schizophrenia is one of the world's 10 leading causes of disabilityadjusted life years and, despite current progress in research and treatment, continues to be a major etiologic, diagnostic, and therapeutic challenge ${ }^{1}$. It has been estimated that around $1 \%$ of the world population suffers from this chronic and disabling disorder. The onset of schizophrenia usually occurs in late adolescence or early adult life, meaning great losses in educational, social, and economic outcomes for individuals and for society as a whole ${ }^{2}$. Currently available evidence suggests that schizophrenia occurs as the result of a combination of genetic, environmental, and social risk factors ${ }^{3}$.

The clinical presentation of schizophrenia is heterogeneous and its manifestations vary among patients and during the course of the disorder ${ }^{4}$. Symptoms can be divided into five dimensions or syndromes: positive (delusions and hallucinations), negative (affective flattening, avolition, anhedonia, social isolation, and alogy), cognitive (executive dysfunction, memory and attention), disorganization (disorganized speech and behavior) and affective (depression, anxiety, dysphoria and mania) ${ }^{5}$.

Functional neuroimaging studies have proved to be an invaluable source of information about the physiopathology of schizophrenia. Many of these studies use radiation-based tracers, like positron emission tomography (PET) and single-photon emission computed tomography (SPECT $)^{6}$. In addition, a growing number of studies have been carried out using newer functional magnetic resonance imaging (fMRI) methods that are able to effectively evaluate brain function without the use of radiation. Blood-oxygen level dependency (BOLD) and arterial spin labeling (ASL) are among these methods. BOLD uses the concentration of deoxyhemoglobin as an endogenous tracer to estimate brain metabolism. The concentration of deoxyhemoglobin is dependent upon regional cerebral blood flow ( $\mathrm{rCBF}$ ), local rate of oxygen consumption, and regional cerebral blood volume ${ }^{7}$. ASL, on the other hand, is based on the quantification of the water flow within brain regions, which is considered to provide an indirect measure of metabolism ${ }^{8}$.
In ASL, the tracer is a magnetic label (tag) applied to water molecules of flowing blood prior to their reaching the region under assessment. Such labeling consists in an inversion of proton spins of arterial water. After an interval that allows water molecules to be exchanged within tissues, an image, referred to as 'labeled' or 'tagged', is acquired. In this image, blood water is in a different magnetization state from that of static tissue water. Also, a control image of the same slice is acquired in which inflowing blood is not labeled. By calculating the difference between control and tagged images, investigators can create an image that corresponds to the proportional $\mathrm{rCBF}$ in a given brain region ${ }^{8}$.

Four types of ASL spin preparation methods are used currently: pulsed ASL (PASL), continuous ASL (CASL), pseudo-continuous ASL (pCASL), and velocity-selective ASL (VS-ASL). The difference between these methods lies in the method used to magnetically tag water molecules in inflowing blood (Figure 1)9.

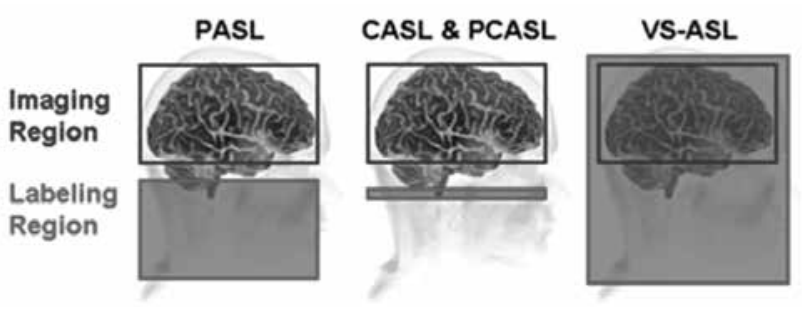

Figure 1. Tagging method for the acquisition of different arterial spin labeling (ASL) sequences. Pulsed ASL (PASL) inverts a great portion of spins (unmoving and moving) proximal to the imaging region. Continuous and pseudo-continuous ASL (CASL and pCASL) labels a narrow plane of spins continuously proximal to the imaging region. Velocity selective ASL (VS-ASL) selectively tags moving spins of a certain velocity to measure perfusion. Figure extracted from Huan et al. 45 . 
PASL uses short (5-20 ms) radio-frequency (RF) pulses in a large plane proximal to the imaging region as the method of spin inversion. CASL uses long and continuous RF pulses (1-2 s) along with a constant gradient field to induce an inversion in a narrow plane of spins, usually applied at the base of the brain. pCASL was introduced to eliminate the CASL demand on hardware and reduce $\mathrm{RF}$ pulses. This technique uses a train of discrete RF pulses in combination with synchronous gradient fields to mimic CASL. VS-ASL selectively inverts spins based on blood velocity rather than spatial location. In comparison with the other techniques, pCASL has a higher efficiency, easier implementation, and less hardware overload 9 .

ASL is a promising method to study brain metabolism noninvasively and without the need for radiotracers and, despite having been in use for some time in schizophrenia patients, no systematic reviews have been published to date on this topic. Our objective, therefore, was to make a systematic review of case-control studies that used ASL to compare resting-state rCBF patterns in patients with schizophrenia and healthy controls.

\section{Methods}

We performed a systematic search for case-control studies that compared resting-state $\mathrm{rCBF}$ in patients with schizophrenia and healthy controls. No limits of age, language or publication date were set for the searches, but articles describing interventions and assessing $\mathrm{rCBF}$ in conditions other than resting-state studies were excluded. Methods of rCBF quantification should be one of the ASL techniques listed above. Diagnostic criteria should be ICD-10, DSM IV/V or other validated method.

The articles to be included in the review were searched for in electronic databases (PubMed, PsycINFO, Web of Science, and Scopus) and through hand search of the reference lists of articles found in the databases. The last search was performed on June 10, 2015 by two of the authors using the search terms 'schizophrenia', 'arterial', 'spin', 'labeling. No filters were applied in the searches.
The process of article search and selection followed the guidelines proposed in the PRISMA (Preferred Reporting Items for Systematic Reviews and Meta-Analyses) statement ${ }^{10}$.

One reviewer assessed the eligibility of articles for inclusion in the review in an unblinded manner, that is, the title and abstract of all articles found using the search terms were read in order to apply the inclusion criteria, and articles pre-selected in this initial assessment were read in full to refine the selection process and exclude articles that failed to fulfill the inclusion criteria or include new ones from the reference lists of the articles reviewed. Another author used a data extraction table designed to collect data from the articles included, which was then checked by a third author for accuracy. The data extraction table included information on (1) characteristics of trial participants, (2) type of ASL, (3) type of MRI equipment and (4) rCBF outcomes.

The primary outcome of this review was the comparison of relative $\mathrm{rCBF}$ between patients and healthy controls, that is, the presence of increased or decreased $\mathrm{rCBF}$ in one group relative to the other. For the purpose of this review, the results presented in the articles were considered convergent if two or more studies obtained an identical outcome for the same region, and divergent if two or more studies obtained different outcomes for the same region. Superimposed regions were not considered. For example, if one study reported increased $\mathrm{rCBF}$ in the superior corona radiata and another one described the same result in the corona radiata as a whole, this was not considered a convergent result.

\section{Results}

\section{General characteristics of reviewed articles}

The process of article search and selection is summarized in Figure 2. As shown, 22 articles were excluded after examination of their titles and abstracts as they clearly did not meet the inclusion criteria of the review. The flow diagram also details the reasons for the exclusion of 5 of the 15 articles selected in the initial step.

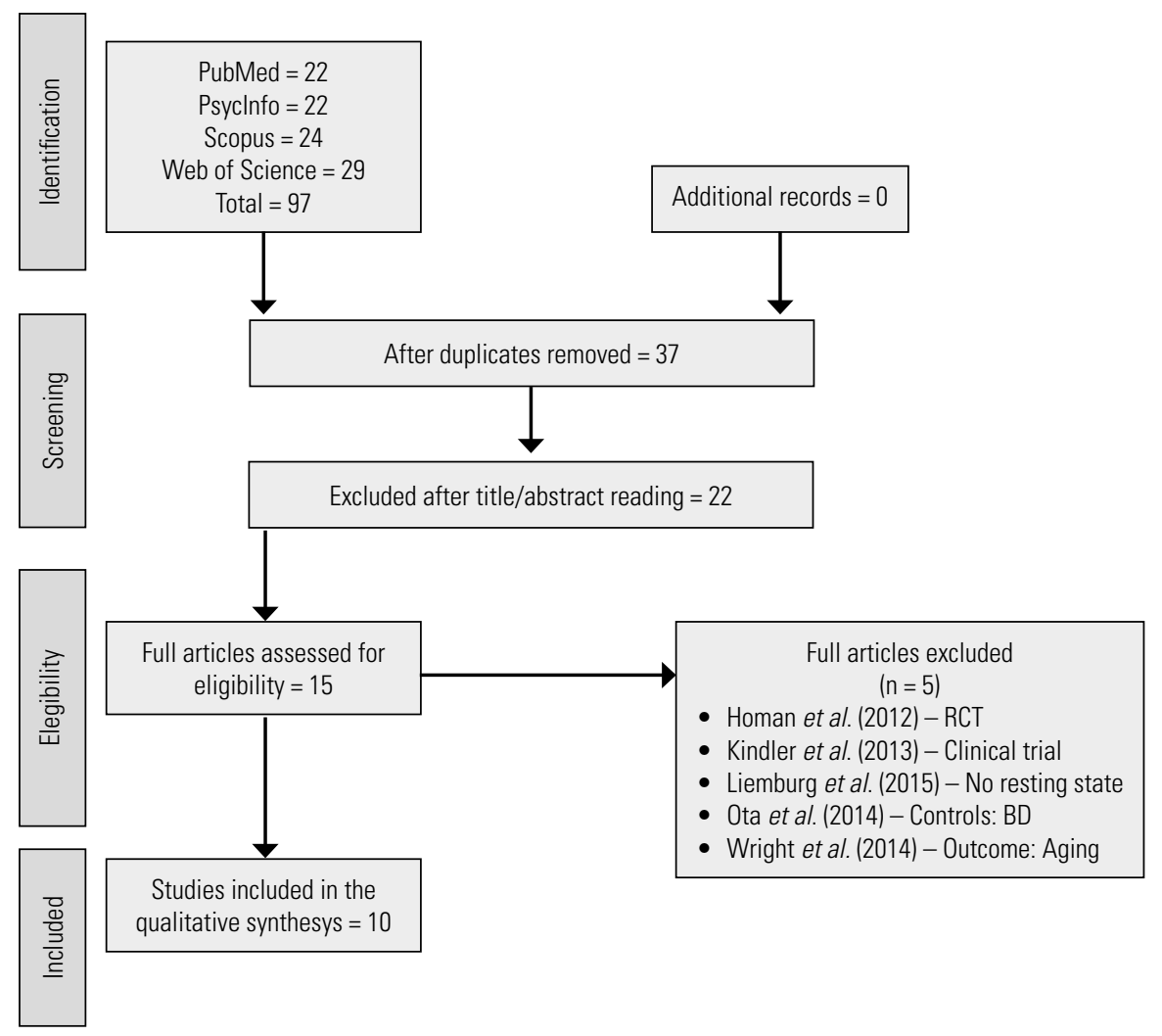

Figure 2. Flow diagram showing the procedure of article search and selection. RCT: randomized controlled trial; BD: bipolar affective disorder. 
Among the articles included in the review, 10 were case-control studies published in English. Table 1 shows the main characteristics of the articles included in the review. All the studies used DSM-IV/V or ICD-10 criteria for diagnosis, except for the one by Pinkham et al. ${ }^{11}$, who used the Diagnostic Interview for Genetic Studies. Homan et al. ${ }^{12}$ investigated only one region of interest, the left superior temporal gyrus, in patients with medication-resistant auditory verbal hallucinations. All the other studies performed whole-brain analysis.

\section{Outcomes}

\section{Convergent results}

The main outcomes of the articles reviewed are summarized in Table 2. No qualitative distinctions were found between different ASL techniques. All the articles reported significant differences between schizophrenia patients and healthy controls, except for the one by Horn et al. ${ }^{13}$, which was the only study to find no differences in rCBF between patients and controls (although the authors found a positive correlation between formal thought disorder and $\mathrm{rCBF}$ ). It should be mentioned here that the study by Horn et al. ${ }^{13}$ did not acquire images from superior regions of the brain because of technical limitations.

\section{Divergent results}

Divergent $\mathrm{rCBF}$ results were found in five regions of the brain. Of note, most of the divergent findings were described in the same study, by Scheef et al. ${ }^{14}$ (see Table 3 for details).
Table 2. Convergent results in the articles reviewed. Increases or decreases in $\mathrm{rCBF}$ are relative to healthy controls

\begin{tabular}{|c|c|c|c|}
\hline Brain region & $\uparrow C B F$ & $\downarrow C B F$ & $\begin{array}{l}\text { Total of } \\
\text { patients }\end{array}$ \\
\hline ACC & & $\begin{array}{l}\text { Kindler et al. (2013) } \\
\text { Scheef et al. (2010) } \\
\text { Zhu et al. (2015) }\end{array}$ & 145 \\
\hline $\mathrm{CN}$ & & $\begin{array}{l}\text { Kindler et al. (2013) } \\
\text { Pinkham et al. (2015) } \\
\text { Scheef et al. (2010) }\end{array}$ & 77 \\
\hline $\mathrm{FF}$ & & $\begin{array}{c}\text { Kindler et al. (2013) } \\
\text { Pinkham et al. (2015) }\end{array}$ & 66 \\
\hline $\mathrm{FL}$ & & $\begin{array}{l}\text { Kindler et al. (2013) } \\
\text { Scheef et al. (2010) }\end{array}$ & 45 \\
\hline IFG & & $\begin{array}{l}\text { Pinkham et al. (2011) } \\
\text { Pinkham et al. (2015) }\end{array}$ & 62 \\
\hline LG & & $\begin{array}{l}\text { Kindler et al. (2013) } \\
\text { Pinkham et al. (2011) }\end{array}$ & 64 \\
\hline L_MFG & & $\begin{array}{l}\text { Pinkham et al. (2011) } \\
\text { Zhu et al. (2015) }\end{array}$ & 130 \\
\hline MOG & & $\begin{array}{c}\text { Pinkham et al. (2011) } \\
\text { Pinkham et al. (2015) } \\
\text { Zhu et al. (2015) }\end{array}$ & 162 \\
\hline $\mathrm{PL}$ & & $\begin{array}{l}\text { Kindler et al. (2013) } \\
\text { Scheef et al. (2010) }\end{array}$ & 45 \\
\hline Put & $\begin{array}{l}\text { Pinkham et al. (2011) } \\
\text { Zhu et al. (2015) }\end{array}$ & & 130 \\
\hline
\end{tabular}

ACC: anterior cingulate cortex; $r C B F$ : regional cerebral blood flow; $C N$ : cuneus; FF: fusiform gyrus; FL: frontal lobe; IFG: inferior frontal gyrus; LG: lingual gyrus; L_MFG: left middle frontal gyrus; MOG: middle occipital gyrus, PL: parietal lobe; Put: putamen.

Table 1. Characteristics of the articles included in the review

\begin{tabular}{|c|c|c|c|c|c|c|c|}
\hline Study & ASL Technique - T & Patients (F/M) & $\begin{array}{l}\text { Patients age } \\
\text { (mean/SD) }\end{array}$ & Duration of illness & Age of onset & $\begin{array}{l}\text { CLPZ Eq. - mg/day } \\
\text { (mean/SD) }\end{array}$ & PANSS (mean/SD) \\
\hline Homan et al. (2013) & $\begin{array}{c}\text { pCASL } \\
3 T\end{array}$ & $11(8 / 3)$ & $37.1(8.8)$ & na & $23.3(4.4)$ & 714.5 (475.5) & $67.1(18.9)$ \\
\hline Horn et al. (2009) & $\begin{array}{l}\text { PASL } \\
1,5 T\end{array}$ & $13(5 / 8)$ & $29.6(11.2)$ & $2.79(2.6)$ & na & 556.2 (na) & $63.9(16.7)$ \\
\hline Kindler et al. (2013) & $\begin{array}{c}\text { pCASL } \\
3 T\end{array}$ & $34(16 / 18)$ & $41.5(12.9)$ & na & na & $518.9(235.7)$ & $75.5(17.3)$ \\
\hline Liu et al. (2012) & $\begin{array}{l}\text { PASL } \\
3 T-\end{array}$ & $19(8 / 11)$ & na & $20.5(10)$ & $26(8.9)$ & $622.1(418)$ & na \\
\hline Ota et al. (2014) & $\begin{array}{c}\text { pCASL } \\
3 T\end{array}$ & $36(19 / 17)$ & $37.9(13)$ & $16.8(11.3)$ & na & $604.8(459.2)$ & $61.8(19.3)$ \\
\hline $\begin{array}{l}\text { Pinkham et al. } \\
\text { (2011) }\end{array}$ & $\begin{array}{c}\text { PASL } \\
3 T\end{array}$ & $30(12 / 18)$ & $35.7(10)$ & na & na & 373.7 (333.4) & na \\
\hline $\begin{array}{l}\text { Pinkham et al. } \\
\text { (2015) }\end{array}$ & $\begin{array}{c}\text { pCASL } \\
3 T\end{array}$ & $\begin{array}{c}16(8 / 8) \\
16(5 / 11)\end{array}$ & $\begin{array}{c}38.5(7.7) \\
38.8(13.2)\end{array}$ & na & na & $\begin{array}{l}332.2(371.2) \\
350.5(546.7)\end{array}$ & $\begin{array}{c}32(5.3) \\
25.1(5.5)\end{array}$ \\
\hline Scheef et al. (2010) & $\begin{array}{c}\text { CASL } \\
3 T\end{array}$ & $11(3 / 8)$ & $32(5)$ & na & na & un & 43.1 (8.5) \\
\hline $\begin{array}{l}\text { Walhter et al. } \\
\text { (2011) }\end{array}$ & $\begin{array}{c}\text { PASL } \\
3 T\end{array}$ & $11(3 / 8)$ & $35.3(12.5)$ & $8.9(13.2)$ & na & $442.5(241)$ & $54.2(14.11)$ \\
\hline Zhu et al. (2015) & $\begin{array}{c}\text { pCASL } \\
3 T\end{array}$ & $100(43 / 57)$ & $33.6(8.6)$ & $10.2(8.2)$ & na & 453.2 (342.9) & $71.3(22.7)$ \\
\hline$n=10$ & $\begin{array}{c}\text { pCASL } \\
\text { 3T (mode) }\end{array}$ & $\begin{array}{c}\text { Total }=297 \\
\text { Mean }=29.7 \\
\text { Median }=24.5 \\
S D=26.7\end{array}$ & $\begin{array}{c}\text { Mean }=36 \\
\text { Median }=36.4 \\
\mathrm{SD}=3.53\end{array}$ & & & $\begin{array}{c}\text { Mean }=496.86 \\
\text { Median }=486.05 \\
S D=127.9\end{array}$ & $\begin{array}{c}\text { Mean }=54.8 \\
\text { Median }=61.8 \\
\text { SD }=17.7\end{array}$ \\
\hline
\end{tabular}

ASL: arterial spin labeling; CASL: continuous ASL; CLPZ Eq: chlorpromazine equivalents; F: female; ID: illness duration; M: male; na: not available; PASL: pulsed ASL; pCASL: pseudocontinuous ASL; SD: standard deviation; T: Tesla. 
Table 3. Divergent results in the articles reviewed. Increases or decreases in $\mathrm{rCBF}$ are relative to healthy controls

\begin{tabular}{|c|c|c|}
\hline Brain region & $\uparrow \mathrm{CBF}$ & $\downarrow \mathrm{CBF}$ \\
\hline R_MTG & $\begin{array}{c}\text { Pinkham et al. (2011) } \\
n=30\end{array}$ & $\begin{array}{c}\text { Scheef et al. (2010) } \\
n=11\end{array}$ \\
\hline L_MTG & $\begin{array}{l}\text { Zhu et al. (2015) } \\
n=100\end{array}$ & $\begin{array}{c}\text { Walther et al. (2011) } \\
n=11\end{array}$ \\
\hline PHG & $\begin{array}{c}\text { Scheef et al. (2010) } \\
n=11\end{array}$ & $\begin{array}{l}\text { Walther et al. (2011) } \\
\quad \mathrm{n}=11\end{array}$ \\
\hline PCN & $\begin{array}{c}\text { Scheef et al. (2010) } \\
n=11\end{array}$ & $\begin{array}{c}\text { Pinkham et al. (2011) } \\
n=30\end{array}$ \\
\hline Th & $\begin{array}{c}\text { Scheef et al. (2010) } \\
\text { Zhu et al. (2015) } \\
\mathrm{n}=111\end{array}$ & $\begin{array}{c}\text { Liu et al. (2012) } \\
\text { Walther et al. (2011) } \\
\quad \mathrm{n}=30\end{array}$ \\
\hline
\end{tabular}

rCBF: regional cerebral blood flow; R_MTG: right middle temporal gyrus; L_MTG: left middle temporal gyrus; PHG: parahipoccampal gyrus; PCN: precuneus; Th: thalamus.

\section{Discussion}

Taken together, the findings of our review lends support to the disputed hypothesis of hypofrontality in schizophrenia patients ${ }^{15}$. Convergent findings of decreased $\mathrm{rCBF}$ were reported in the frontal lobe (FL), left middle frontal gyrus (eMiFG), and inferior frontal gyrus (IFG). These regions are closely related to the regulation of complex behaviors that are impaired in schizophrenia ${ }^{16}$. Pinkham et al. ${ }^{17}$ found a frontal region with increased $\mathrm{rCBF}$, the right precentral gyrus, but no explanation was given for this finding and no other study in our review found similar results in this region or in any other frontal region.

The anterior cingulate (ACC) is responsible for the integration of cognitive and emotional processes in goal-directed activities. Clinically, these functions are impaired in schizophrenia patients. Convergent results of decreased $\mathrm{rCBF}$ in the ACC are consistent with clinical observations and other imaging studies ${ }^{18}$.

The occipital lobe is host to both the primary visual area and the visual association area. Deficits in early-stage visual processing have been repeatedly reported in schizophrenia patients ${ }^{19}$ and visual hallucinations seem to be associated with dysfunctions in this region ${ }^{20}$. Our review found convergent results regarding the $\mathrm{rCBF}$ in three important sub regions of the occipital lobe; the lingual gyrus, cuneus and middle occipital gyrus.

The fusiform gyrus (FF) is an occipitotemporal brain region thought to subserve the processing and encoding of facial stimuli. Several studies have reported that schizophrenia patients show deficits in facial processing ${ }^{21}$. It has been hypothesized that the FF might be the central brain region underlying abnormal facial recognition in schizophrenia ${ }^{22}$. The studies reviewed here provided convergent results of decreased $\mathrm{rCBF}$ in the FF, in support to this hypothesis.

Convergent results of decreased $\mathrm{rCBF}$ were also found in the parietal lobe, a region that is recruited when one views one's own body compared with a familiar body and which stores representations of the self-face as part of one's awareness of the self-body; in sum, this region supports the ability for self-other discrimination ${ }^{23,24}$. The parietal lobe contains mirror neurons and maintains self-other distinction during empathic interpersonal face-to-face interactions. Studies on self-face processing in schizophrenia have provided mixed results to date 25,26 , but our review points to the existence of impairments related to this region.

There is substantial evidence in the literature of abnormal basal ganglia activity in subjects with schizophrenia ${ }^{27}$. The basal ganglia include the following nuclei: caudate nucleus, putamen, nucleus accumbens, globus pallidus, subthalamic nucleus, and the mesencephalic nuclei of the substantia nigra and ventral tegmental area. Through extensive cortical connections, these nuclei are implicated in motor and cognitive functions ${ }^{28}$. For example, affective flattening has been correlated with anterior putamen abnormalities in non-medicated patients ${ }^{29}$. Our finding of increased $\mathrm{rCBF}$ in the putamen is in line with the results of studies using other neuroimaging methods and is probably a consequence of antipsychotic use ${ }^{30}$.

The middle temporal gyrus (MTG) is involved in several cognitive processes, including language and semantic memory processing, and multimodal sensory integration ${ }^{31}$. Functional deficits in these domains have been reported in schizophrenia, and it appears reasonable to assume therefore that the MTG plays an important role in the physiopathology of schizophrenia ${ }^{32,33}$. However, it is not yet clear whether $\mathrm{rCBF}$ in this region is increased or decreased in patients ${ }^{6}$. Among the articles included in our review, Pinkham et al. ${ }^{17}$ $(\mathrm{N}=30)$ reported increased $\mathrm{CCBF}$ in the right MTG in schizophrenia, whereas Scheef et al. ${ }^{14}(\mathrm{~N}=11)$, the only study with unmedicated patients, found decreased $\mathrm{rCBF}$ in patients relative to controls. The assumption of an antipsychotic effect to explain these differences is tempting, but the answer remains elusive. Zhu et al. ${ }^{34}(\mathrm{~N}=100)$ found increased $\mathrm{rCBF}$ in the left MTG, in contrast with Walther et al. ${ }^{35}(\mathrm{~N}=11)$, who described a decrease in patients. It is possible that increased rCBF in the MTG of schizophrenia patients reflects greater effort to integrate various sensory cues, even passively while at rest. Alternatively, it is also possible that increased $\mathrm{rCBF}$ in this region may be related to treatment with antipsychotic medications. The evidence available to date is insufficient to answer these questions.

The parahippocampus is a component of the hippocampal formation, and a key structure for declarative memory ${ }^{36}$. Impaired parahippocampal recruitment during visual-memory encoding has been reported in patients and their siblings ${ }^{37}$. In our review, two small studies with the same sample size found divergent results in this region: while Scheef et al. ${ }^{14}(\mathrm{~N}=11)$ described increased $\mathrm{rCBF}$ in this brain region, Walther et al. ${ }^{35}(\mathrm{~N}=11)$ found precisely the opposite. Again, evidence is not enough to determine the rCBF patterns in the parahippocampus of patients with schizophrenia.

The precuneus is located in the posteromedial portion of the parietal lobe and has important connections with the prefrontal cortex, ACC, and many other areas. It is believed to play a central role in the neural network supporting the mental representation of the self 38 . It has also been hypothesized that the precuneus is part of a few highly-connected regions playing a central role in the global topology of the brain network. Studies have shown that functions mediated by the precuneus are impaired in schizophrenia ${ }^{39}$. Scheef et al..$^{14}(\mathrm{~N}=11)$ reported increased $\mathrm{rCBF}$ in the precuneus of patients, which is in contrast with Pinkham et al. ${ }^{17}(\mathrm{~N}=30)$. The divergent data available make it impossible to determine rCBF patterns in the precuneus of patients with schizophrenia.

The thalamus is an important region in the bidirectional flow of neuronal signals between cortical and subcortical regions; and it also links different cortical regions via transthalamic pathways ${ }^{40}$. Many studies report a variety of thalamic alterations in schizophrenia, but few have offered consistent findings ${ }^{41}$. Our review showed divergent results regarding the $\mathrm{CCBF}$ in the thalamus in schizophrenia, but the studies that found increased $\mathrm{rCBF}$ (Scheef et al..$^{14}$ and Zhu et al. ${ }^{34}$ ), assessed a total of 111 patients against 30 patients assessed by Liu et al. ${ }^{42}$ and Walther et al. ${ }^{35}$ The evidence of increased rCBF in the thalamus of schizophrenia patients receives further support from a PET study ${ }^{43}$, but the discrepancies should be addressed by future research.

\section{Conclusions}

Our review has some limitations that should be taken into account by the reader. First, the qualitative approach for data extraction reduces the strength of our analyses, as our findings could not be the object of statistical treatment. Also, corrections for age, symptomatology, age of onset, illness duration or medication use were not performed. Moreover, schizophrenia research has a few intrinsic limitations related to highly heterogeneity of the disorder, different etiological factors, and the fact that almost every patient is on antipsychotics and recruitment of large samples is a challenge, especially for neuroimaging investigations. 
Despite these limitations, the results of our review highlight the differences in the brain metabolism of schizophrenia patients compared to healthy controls and suggest that ASL is a valid and reliable tool for investigations on the neural underpinnings of the disorder. Our findings are consistent with those of previous studies and lend support to the hipofrontality hypothesis at the same time that they are harmonic with the disconnection hypothesis ${ }^{44}$ of schizophrenia.

The next logical step for future reviews would thus be a quantitative analysis (meta-analysis) of raw $\mathrm{rCBF}$ data, and studies involving larger samples than the ones performed to date will be central for solid conclusions to be reached about the patterns of rCBF in schizophrenia.

\section{Acknowledgements}

No acknowledgements.

\section{References}

1. World Health Organization (WHO). The global burden of disease 2004 .

2. Insel TR. Rethinking schizophrenia. Nature. 2010;468:187-93.

3. Mueser KT, McGurk SR. Schizophrenia. Lancet. 2004;363:2063-72.

4. Tandon R, Nasrallah HA, Keshavan MS. Schizophrenia, "just the facts" 4. Clinical features and conceptualization. Schizophr Res. 2009;110(13):1-23.

5. Peralta V, Cuesta MJ. How many and which are the psychopathological dimensions in schizophrenia? Issues influencing their ascertainment. Schizophr Res. 2001;49(3):269-85.

6. Davidson LL, Heinrichs RW. Quantification of frontal and temporal lobe brain-imaging findings in schizophrenia: a meta-analysis. Psychiatry Res. 2003;122(2):69-87.

7. Norris DG. Principles of magnetic resonance assessment of brain function. J Magn Reson Imaging. 2006;23:794-807.

8. Borogovac A, Asllani I. Arterial Spin Labeling (ASL) fMRI: advantages, theoretical constrains, and experimental challenges in neurosciences. Int J Biomed Imaging. 2012;2012:818456.

9. Pollock JM, Tan H, Kraft RA, Whitlow CT, Burdette JH, Maldjian JA. Arterial spin-labeled MR perfusion imaging: clinical applications. Magn Reson Imaging Clin N Am. 2009;17(2):315-38.

10. Liberati A, Altman DG, Tetzlaff J, Mulrow C, Gøtzsche PC, Ioannidis JP, et al. The PRISMA statement for reporting systematic reviews and metaanalyses of studies that evaluate health care interventions: explanation and elaboration. J Clin Epidemiol. 2009;62(10):e1-34.

11. Pinkham AE, Liu P, Lu H, Kriegsman M, Simpson C, Tamminga C. Amygdala Hyperactivity at Rest in Paranoid Individuals With Schizophrenia. Am J Psychiatry. 2015;172:784-92.

12. Homan P, Kindler J, Hauf M, Walther S, Hubl D, Dierks T. Repeated measurements of cerebral blood flow in the left superior temporal gyrus reveal tonic hyperactivity in patients with auditory verbal hallucinations: a possible trait marker. Front Hum Neurosci. 2013;7:304

13. Horn H, Federspiel A, Wirth M, Muller TJ, Wiest R, Wang J-J, et al. Structural and metabolic changes in language areas linked to formal thought disorder. Br J Psychiatry. 2009;194(2):130-8.

14. Scheef L, Manka C, Daamen M, Kühn K-U, Maier W, Schild HH, et al. Resting-state perfusion in nonmedicated schizophrenic patients: a continuous arterial spin-labeling 3.0-T MR study. Radiology. 2010;256(1):253-60.

15. Gur R, Gur R. Hypofrontality in schizophrenia: RIP. Lancet. 1995;345(8962):1383-4

16. Salgado-Pineda $\mathrm{P}$, Caclin A, Baeza I, Junqué C, Bernardo M, Blin O, et al. Schizophrenia and frontal cortex: where does it fail? Schizophr Res. 2007;91(1-3):73-81.

17. Pinkham A, Loughead J, Ruparel K, Wu WC, Overton E, Gur RR, et al. Resting quantitative cerebral blood flow in schizophrenia measured by pulsed arterial spin labeling perfusion MRI. Psychiatry Res. 2011;194(1):64-72.

18. Reid MA, Stoeckel LE, White DM, Avsar KB, Bolding MS, Akella NS, et al. Assessments of function and biochemistry of the anterior cingulate cortex in schizophrenia. Biol Psychiatry. 2010;68(7):625-33.
19. Butler PD, Schechter I, Zemon V, Schwartz SG, Greenstein VC, Gordon J, et al. Dysfunction of early-stage visual processing in schizophrenia. Am J Psychiatry. 2001;158(7):1126-33.

20. Onitsuka T, McCarley RW, Kuroki N, Dickey CC, Kubicki M, Demeo SS, et al. Occipital lobe gray matter volume in male patients with chronic schizophrenia: A quantitative MRI study. Schizophr Res. 2007;92(13):197-206

21. de Sousa JPM, Hallak JEC. Facial information processing in schizophrenia. Psychol Neurosci. 2008;1(1):21-6.

22. Onitsuka T, Shenton ME, Kasai K, Nestor PG, Toner SK, Kikinis R, et al. Fusiform gyrus volume reduction and facial recognition in chronic schizophrenia. Arch Gen Psychiatry. 2003;60(4):349-55.

23. Hodzic A, Muckli L, Singer W, Stirn A. Cortical responses to self and others. Hum Brain Mapp. 2009;30(3):951-62.

24. Platek SM, Loughead JW, Gur RC, Busch S, Ruparel K, Phend N, et al. Neural substrates for functionally discriminating self-face from personally familiar faces. Hum Brain Mapp. 2006;27(2):91-8.

25. Kircher TT, Seiferth NY, Plewnia C, Baar S, Schwabe R. Self-face recognition in schizophrenia. Schizophr Res. 2007;94(1-3):264-72.

26. Lee J, Kwon JS, Shin Y-W, Lee KJ, Park S. Visual self-recognition in patients with schizophrenia. Schizophr Res. 2007;94(1-3):215-20.

27. Menon V, Anagnoson RT, Glover GH, Pfefferbaum A. Functional magnetic resonance imaging evidence for disrupted basal ganglia function in schizophrenia. Am J Psychiatry. 2001;158(4):646-9.

28. Parent A, Hazrati LN. Functional anatomy of the basal ganglia. I. The cortico-basal ganglia-thalamo-cortical loop. Brain Res Brain Res Rev. 1995;20(1):91-127.

29. Ballmaier M, Schlagenhauf F, Toga A, Gallinat J, Koslowski M, Zoli M, et al. Regional patterns and clinical correlates of basal ganglia morphology in non-medicated schizophrenia. Schizophr Res. 2008;106(2-3):140-7.

30. Lahti AC, Holcomb HH, Weiler MA, Medoff DR, Tamminga CA. Functional effects of antipsychotic drugs: comparing clozapine with haloperidol. Biol Psychiatry. 2003;53(7):601-8.

31. Chao LL, Haxby J V, Martin A. Attribute-based neural substrates in temporal cortex for perceiving and knowing about objects. Nat Neurosci. 1999;2(10):913-9.

32. Kuperberg GR, McGuire PK, David AS. Reduced sensitivity to linguistic context in schizophrenic thought disorder: evidence from on-line monitoring for words in linguistically anomalous sentences. J Abnorm Psychol. 1998;107(3):423-34.

33. Nestor PG, Akdag SJ, O’Donnell BF, Niznikiewicz M, Law S, Shenton $\mathrm{ME}$, et al. Word recall in schizophrenia: a connectionist model. Am J Psychiatry. 1998;155(12):1685-90.

34. Zhu J, Zhuo C, Qin W, Xu Y, Xu L, Liu X, et al. Altered resting-state cerebral blood flow and its connectivity in schizophrenia. J Psychiatr Res. 2015;63:28-35.

35. Walther S, Federspiel A, Horn H, Razavi N, Wiest R, Dierks T, et al. Resting state cerebral blood flow and objective motor activity reveal basal ganglia dysfunction in schizophrenia. Psychiatry Res. 2011;192(2):117-24.

36. Schacter DL, Wagner AD. Medial temporal lobe activations in fMRI and PET studies of episodic encoding and retrieval. Hippocampus. 1999;9(1):7-24.

37. Rasetti R, Mattay VS, White MG, Sambataro F, Podell JE, Zoltick B, et al. Altered hippocampal-parahippocampal function during stimulus encoding: a potential indicator of genetic liability for schizophrenia. JAMA Psychiatry. 2014;71(3):236-47.

38. Cavanna AE, Trimble MR. The precuneus: a review of its functional anatomy and behavioural correlates. Brain. 2006;129(Pt 3):564-83.

39. van den Heuvel MP, Sporns O, Collin G, Scheewe T, Mandl RCW, Cahn $\mathrm{W}$, et al. Abnormal rich club organization and functional brain dynamics in schizophrenia. JAMA Psychiatry. 2013;70(8):783-92.

40. Sherman SM, Guillery RW. The role of the thalamus in the flow of information to the cortex. Philos Trans R Soc Lond B Biol Sci. 2002;357(1428):1695-708.

41. Byne W, Hazlett EA, Buchsbaum MS, Kemether E. The thalamus and schizophrenia: current status of research. Acta Neuropathol. 2009;117(4):347-68.

42. Liu J, Qiu M, Constable RT, Wexler BE. Does baseline cerebral blood flow affect task-related blood oxygenation level dependent response in schizophrenia? Schizophr Res. 2012;140(1-3):143-8.

43. Andreasen NC, O'Leary DS, Flaum M, Nopoulos P, Watkins GL, Boles Ponto LL, et al. Hypofrontality in schizophrenia: distributed 
dysfunctional circuits in neuroleptic-naïve patients. Lancet (London, England). 1997;349(9067):1730-4.

44. Stephan KE, Baldeweg T, Friston KJ. Synaptic plasticity and dysconnection in schizophrenia. Biol Psychiatry. 2006;59(10):929-39.
45. Huan Tan B, Kraft RA, James Daunais CB, Hamilton CA, Scott Hoge $\mathrm{W}$, Plemmons RJ. Improving the robustness of perfusion imaging with arterial spin labeling magnetic resonance imaging. Wake Forest University Graduate School of Arts and Sciences; 2010. 